\title{
Tervishoiusüsteem Harjumaal 1922-1926: töötajad, asutused, arstiabi kättesaadavus
}

Kristina Oganjan

\begin{abstract}
Teesid: Artiklis antakse ülevaade Harjumaa tervishoiust aastatel 1922-1926: uuritakse arstiabi kättesaadavust, meditsiinipersonali ja tervishoiuasutusi. Uurimusest selgub, kui keeruline oli sel ajal tervishoid Harjumaal - arstiabi oli kallis, arsti juurde pääseda raske ja osades arstijaoskondades puudus meditsiinipersonal. Ka olid paljud tervishoiutöötajad ülekoormatud ja alamakstud. Kuna arstiabi kättesaadavus oli kohati vilets ja haiged tihtipeale ei usaldanud tervishoiutöötajaid, eelistasid harjumaalased otsida vajadusel abi rahvameditsiinist. Antud artiklis on kasutatud eelkõige primaarallikaid Tallinna Linnaarhiivist ja osaliselt ka sekundaarseid allikad.
\end{abstract}

Märksõnad: ajalugu, apteek, arstiabi, Harjumaa, meditsiin, tervishoid

Antud artikli eesmärk on tutvustada Eesti riigi toetatud tervishoiusüsteemi Harjumaal $^{1}$ aastatel 1922-1926 ja anda ülevaade seni väheuuritud teemast. Jälgin artiklis, kes moodustasid meditsiinipersonali Harjumaal, millised olid nende tööülesanded, millised olid Harjumaa tervishoiuasutused ning kuivõrd kättesaadav olid arstiabi ja tervishoiuasutuste teenused Harjumaa maapiirkonna inimestele. Et tegemist on suhteliselt uurimata alaga, on kasutatud ennekõike Tallinna Linnaarhiivis asuvaid allikaid. Aleksander Rammul on sama teemat väga lühidalt käsitlenud väljaandes Harjumaa tervishoiuline kirjeldus (1937). Et seni on tervishoiu kohta kirjutatud vähe ja väga üldiselt, olen otsustanud tugineda primaarallikatele. Ka ei käsitle ma rahvameditsiini, kuigi see oli neil aastatel arvatavasti peamine ravimisviis. Rahvameditsiini laialdasest levikust annab aimu sanitaar-topograafiline arhiiv, kus on ka mõningad ravimisviisid välja toodud. Rahvameditsiini on vaja uurida eraldi, ja käesolev uurimus võiks olla selle eeldus: see aitab mõista, miks veel 1920. aastatel eelistasid inimesed rahvameditsiini riiklikult toetatud meditsiinile. 


\section{Meditsiinipersonal}

Harjumaal töötas aastail 1922-1925 jaoskonnaarste, ämmaemandaid, kaks desinfektorit ja üks halastajaõde (TLA 884. 5. 92, lk 9; TLA 884. 5. 118, lk 16). Jaoskonnaarstide ja ämmaemandate arv kõikus pidevalt ning üks jaoskonnaarst võis ära teha mitme jaoskonnaarsti töö, seega on raske öelda, kui palju meditsiinilist personali Harjumaa maapiirkondades töötas. Võib arvata, et neid oli kahekümne-kolmekümne vahel. 1925. aastal lahkusid üks desinfektor ja halastajaõde. Nende asemele uusi meditsiinitöötajaid tööle ei võetud (TLA 884. 5. 132, lk 87), seega oli alates 1925. aastast Harjumaal lisaks arstidele ja ämmaemandatele üks desinfektor. Asjaolu, et kahe lahkunud töötaja asemele uusi ei võetud, näitab, et tervishoiuosakond arvas nakkushaigused kontrolli all olevat - desinfektorite ja halastajaõe peamiseks tööülesandeks oli just nakkushaigustega võitlemine (TLA 884. 5. 106, lk 130). Tagantjärele olukorda vaagides võib tõesti öelda, et 1924. aasta lõpus ja 1925. aasta alguses võis täheldada nakkushaiguste vähenemist, kuid 1926. aastal oli Harjumaal tõsine leetrite puhang ja algas suur sarlakitesse haigestumine, mis jätkus ka aastal 1927 (Oganjan 2008: 39-43, 69-70). Seega tegelikult nakkushaiguste levikut 1925. aastaks veel kontrolli alla ei saadud.

Ka jaoskonnaarstide üks olulisimaid tööülesandeid oli nakkushaiguste vastu võitlemine, sest need olid Harjumaal tõsiseks probleemiks (Oganjan 2008: 39-43, 69-70). Kui kuskil esines mõni nakkushaiguse juhtum, pidi arst kiiresti kindlaks tegema, mis haigusega on tegemist (TLA 884. 5. 71, lk 38; TLA 884. 5. 139, lk 217) ja teavitama sellest ka Tervishoiu Peavalitsust (Tallinn 1924: 35). Seejärel pidi arst tegema kõik võimaliku, et takistada haiguse levikut (TLA 884. 5. 71, lk 38; TLA 884. 5. 139, lk 217). See võis tähendada haige majapidamisele toiduainete väljaviimise ja müügi keeldu (RT 1924: 304). Lisaks nakkushaiguste vastu võitlemisele ravisid arstid jaoskonna elanikke ja andsid neile vajadusel nõu (TLA 884. 5. 71, lk 38; TLA 884. 5. 139, lk 217). Arstid püüdsid jaoskonna elanikke ka meditsiiniliselt harida, teha selgitustööd, sest inimeste seas olid levinud valed arusaamad haigustest ja hügieenist (TLA 884. 5. 97, lk 9). Jaoskonnaarst oli ka kooliarst ja ta pidi üks kord poole aasta jooksul üle vaatama kõik jaoskonna piirkonnas asuvad koolid ja kooliõpilased. Samuti pidi jaoskonnaarst korra poole aasta jooksul üle vaatama vaestemajad ja vaesed. Jaoskonnaarsti ülesandeks oli veel jaoskonnas tervishoiu alal töötava personali järele valvamine (TLA 884. 5. 71, lk 38; TLA 884. 5. 139, lk 217; Karjahärm \& Sirk 2001: 126). Avalike asutuste, söögi- ja joogivalmistamisega tegelevate ettevõtete ning kõikide vabrikute tervishoidlik järelevalve kuulus samuti jaoskonnaarstide tööülesannete hulka (TLA 884. 5. 92, lk 46). Lisaks eelmainitule lahkasid jaoskonnaarstid laipu, näiteks 1925. aastal 
toimus Harjumaal 96 lahkamist (TLA 884. 5. 132, lk 89). Ülesandeid ja töid oli jaoskonnaarstidel tõesti palju, siit ka nende nurin liiga väikese palga üle (TLA 884. 5. 92, lk 46).

Jaoskonnaarstid olid oma piirkonnas vägagi lugupeetud, sest tegemist oli haritud inimestega. Jaoskonnaarstiks võisid saada Tartu Ülikooli arstiteaduskonna lõpetanud mõlemast soost Eesti Vabariigi kodanikud, kes tegutsesid Eesti Vabariigis ja olid registreerunud vastavate seaduste järgi. Väljaspool Eestit arstiks õppinud või ka Eesti kodakondsuseta arstid võisid saada loa kutsetegevuseks tervishoiu peavalitsusest tingimusel, et nad oskavad riigikeelt (TLA 884. 5. 97, lk 17). Ämmaemandate, desinfektorite, halastajaõdede kohta pole selliseid nõudmisi säilinud. Seega pidi ainult jaoskonnaarstidel olema arsti haridus - ülejäänud meditsiinipersonalil polnud seda vaja.

Ülejäänud meditsiinipersonali tööülesanded jagunesid nõnda: ämmaemandate põhitöö oli sünnitusabi osutamine ning vajadusel eel- ja järelravimine (TLA 884. 5. 139, lk 217), vanem-desinfektori peamine ülesanne oli arstide aitamine võitluses nakkushaigustega. Lisaks tegeles vanem-desinfektor piirituseostulubade väljakirjutamise, inventuuride läbiviimise ja muu kontoritööga. Noorem-desinfektor tegeles samuti nakkushaiguste vastu võitlemisega. Lisaks korrastas ta pabereid ja nõudis Tallinna Keskhaiglas ravil olnud Harjumaa elanikelt välja võlgu jäänud ravikulusid. Halastajaõe, nagu ka desinfektorite, peamine ülesanne oli võitlemine nakkushaigustega, samuti tegeles ta masinakirja ja muude lihtsamate kontoritöödega. Lisaks töötas tervishoiuosakonnas asjaajaja, kuid tema tööks oli peamiselt paberite korrashoid ja kirjavahetuse korraldamine (TLA 884. 5. 106, lk 130). 1925. aastal töölt lahkunud desinfektori ja halastajaõe asemele võeti tööle üks kantseleiametnik, kes võttis üle lahkunud meditsiinitöötajate kontoritööd (TLA 884. 5. 132, lk 87).

\section{Arstiabi kättesaadavus}

Harjumaal oli 1921. aasta seisuga 14 arstijaoskonda: Loksa, Kuusalu, Raasiku, Kose, Juuru, Rapla, Järvakandi, Hageri, Nissi, Risti, Madise, Keila, Nõmme ja Tallinna linna ümbruskonna arstijaoskond (TLA 884. 5. 54, lk 16-17), mis hõlmas linna lähiümbrust. 1926. aastaks oli arstijaoskondi järel 13: Nõmme arstijaoskonda enam polnud (TLA 884. 5. 139, lk 233), arvatavasti ühendati see linnaümbruse arstijaoskonnaga. Et Nõmme jaoskond polnud suur ja seal asus erinevaid erapraksiseid, näiteks 1926. aastal praktiseeris Nõmmel 10 arsti, 12 halastajaõde, 7 ämmaemandat ja 3 hambaarsti (HMVT 1927: 168), ei olnud vajadust eraldi Nõmme arstijaoskonda järele. Samas oli teiste jaoskondade suurus väga erinev: näiteks Madise arstijaoskond teenindas 153,6 ruut- 
kilomeetri suurust maa-ala, ent Kose jaoskond hõlmas 661,7 ruutkilomeetrit. Seega oli Kose jaoskonna äärealadel elavatel inimestel palju pikem maa arstini kui Madise jaoskonna elanikel. Pikka vahemaad haigena läbida oli raske ja kallis. Et haige ei suutnud alati ise arsti juurde minna, kutsuti arste ka koju, mille eest maksis haige, ja mida pikem oli vahemaa arstikabinetist haigeni, seda rohkem pidi haige maksma (TLA 884. 5. 139, lk 217), mis tegi Kose jaoskonna äärealade elanikele arsti kojukutsumise tunduvalt kallimaks kui oli näiteks Madise jaoskonna haigetel.

Ideaaltingimustes oli ette nähtud, et igas arstijaoskonnas elab umbes sama palju inimesi. Selle nimel muudeti vahel ka arstijaoskondade piire, näiteks anti Harju maakonnavalitsuse 16. juuni 1922. aasta otsusega nõusolek Nõmme, Hageri, linnaümbruse, Järvakandi ja Rapla arstijaoskondade piiride muutmiseks (TLA 884. 5. 71, lk 31; TLA 884. 5. 71, lk 31). Vaadates, kui palju mõnes jaoskonnas veel rahvaarv muutunud oli, võib arvata, et arstijaoskondade piiride muutmisi tehti rohkemgi (TLA 884. 5. 54, lk 16-17; TLA 884. 5. 139, lk 233). Kuigi arstijaoskondade piire muudeti, olid mõned arstijaoskonnad teistest palju suuremad. Näiteks 1921. aastal oli Kose arstijaoskonnas 9990 elanikku (1926. aasta seisuga 9261 elanikku), Keila arstijaoskonnas 9481 elanikku (1926. aastal 8806 elanikku), samas pidi Madise jaoskonna arst tegelema vaid 3726 elanikuga (1926. aastal 2283 elanikuga) (TLA 884. 5. 54, lk 16-17; TLA 884. 5. 139, lk 233), seega olid arstijaoskondade suurused vaatamata piiride muudatustele vägagi erinevad ja osade arstide töökoormus palju suurem, mis võis omakorda tähendada pikki järjekordi.

Haiglaid Harjumaal ei olnud, sellepärast oli Harju maavalitsus sõlminud lepingu Tallinna Keskhaiglaga, mille järgi Harju maakonna elanikud said viibida ravil Tallinnas (TLA 884. 5. 106, lk 112). Eesti Vabariigi algusaastatel maksid harjumaalased Tallinna Keskhaiglas ravil viibimise eest $50-100 \%$ rohkem kui tallinlased. Alates 1. aprillist 1922 said Harjumaa elanikud keskhaigla kasutamiseks tallinlastega samad õigused, sest Harju maavalitsus otsustas osa ravikulusid kinni maksta (TLA 884. 5. 71, lk 13). Tallinna Keskhaiglas viibimine maksis alates 1924. aasta 1. jaanuarist 175 marka ööpäev (TLA 808. 1. 210), 1926. aastal tuli Harjumaa elanikel maksta ravi eest Tallinna Keskhaiglas 300 marka ööpäevas (HMVT 1927: 169). Et Harjumaal haiglaid ei olnud ja haiged pidid haiglaravi saamiseks sõitma Tallinnasse, oli see samuti väga kallis. Nii sõit kui ka haiglakulud tegid haiglaravi vaesematele inimestele peaaegu kättesaamatuks.

Ka eriravi sai põhiliselt Tallinnast, aga lisaks oli eriarste Nõmmel, näiteks 1926. aastal tegutses Nõmmel kolm hambaarsti (HMVT 1927: 168). Suguhaiguste korral pöörduti tavaliselt Tallinna eriarstide poole (HMVT 1927: 169). Harjumaal asus ka üks sanatoorium: tuberkuloosihaigetele mõeldud Seli sa- 
natoorium, mida pidas ülal Eesti Punane Rist (TLA 884. 5.106, lk 34). Nii pidid harjumaalased haiglaravi saamiseks tingimata pöörduma Tallinnasse, seevastu eriravi oli võimalik osaliselt saada ka maakonnas.

Kuigi nimetus arstijaoskond viitab, et igas jaoskonnas oleks pidanud olema vähemalt üks arst, 1921. aastaks see nõnda veel polnud. 1921. aastal tegutsesid 14 arstijaoskonnast üheksas arstid, viies arste ei olnud (TLA 884. 5. 54, lk 16-17). Siiski selgub allikatest, et kõikidele arstijaoskondadele maksti palgaraha (TLA 884. 5. 54, lk 16-17), seega võib arvata, et nendes jaoskondades, kus arste polnud, käisid abiks teistes jaoskondades töötavad arstid. 1926. aastaks oli olukord paranenud, nii et igas jaoskonnas oli olemas arst (TLA 885. 5. 139, $1 \mathrm{k} 233$ ). Ka terves Eestis oli arste selleks ajaks maakondades varasemast mitu korda rohkem: 1921. aastal oli maakondades 77 arsti, 1926. aastal aga 191 (Karjahärm \& Sirk 2001: 127). Arstide juurdekasvu põhjustas asjaolu, et esimesed eestikeelsesse ülikooli astunud inimesed asusid lõpetamise järel tööle (Karjahärm \& Sirk 2001: 126).

Ometigi ei tähendanud arsti olemasolu veel, nagu oleks kõik korras. Tervishoiutöötajatega leidis aset mitmeid konflikte, mis tekitasid usaldamatust ja probleeme. Näiteks kogus rahvas allkirju doktor Karro vastu ja põhjusena toodi välja, et ta ei suutnud oma ülesandeid täita või täitis neid halvasti (TLA 884. 5. 74, lk 129). Lahendusena saadeti dr Karro välismaale õppima (TLA 884. $5.74, \mathrm{k} 135$ ). Kui see lugu on pigem erandlik, siis süüdistused, et arstid võtsid lubatust rohkem tasu, oli tavalisem. Tallinna Töölises 25. märtsil 1922. aastal ilmunud artiklis "Üks valusamatest küsimustest" kirjutatakse, kuidas arst küsis lubatud 100 marga asemel lausa 375 marka (TLA 884. 5. 74, lk 113). Harju Maavalitsuse tervishoiuosakond teadis, et arstid rohkem tasu võtsid, samuti teadis osakond, et rahvas ülemaksmise tõttu nuriseb (TLA 884. 5. 74, lk 15), kuid tundub, et probleemide vastu võitlemisega eriti ei tegeldud. Näiteks Raikkülas võttis ämmaemand kooliõpetaja abikaasale osutatud sünnitusabi eest raha, kuigi see oli keelatud. Kui tervishoiuosakond sellest teada sai, keelati ämmaemandal seda teha, aga raha ta ei pidanud tagasi maksma - mitte mingit karistust ei järgnenud (TLA 884. 5. 74, lk 255). Karistamata jätmine lubab arvata, et ämmaemand jätkas vanaviisi. Tervishoiutöötajate lubatust suuremad tasud vähendasid kindlasti usaldust nende vastu ja muutsid vaesematele inimestele arstiabi veelgi kättesaamatumaks. Et aga haiguste jms korral on abi vaja, pöördusidki inimesed tihti rahvameditsiini poole. Näiteks kasutasid Harjumaa elanikud ravimtaimi: ristikheina õitest valmistatud teega raviti erinevaid naistehaigusi (STA (sanitaar-topograafiline arhiiv), Harjumaa 358 (55), Ravila vald), kummeliteega palavikku (STA, Harjumaa, 1923, 455 (55), Triigi vald). Kasutati ka äärmuslikumaid abinõusid, näiteks Ravila vallas prooviti tiisikust ravida uriini joomisega (STA, Harjumaa, 352 (21), Ravila vald). 


\section{Apteegid}

1922. aasta seisuga tegutses Harjumaal 14 apteeki, mis asusid Pirital, Kuusalus, Hageris, Nissis, Jõelähtmes, Ristil, Juurus, Kosel, Keilas, Haljalas, Loksal, Lallikülas, Raplas ja Jüri kiriku juures (TLA 884. 5. 96, lk 56). Neid apteeke kasutas 80360 inimest (TLA 884. 5. 96, lk 56) 91 032-st (Rahvalugemise 1924: 2), sest osa maarahvast käis apteegis Tallinnas, Paldiskis või Nõmmel. Seega oli 5740 inimese kohta keskmiselt üks apteek. Seaduste järgi pidi olema üks apteek iga 6000 elaniku kohta (TLA 884. 5. 96, lk 13) ja see nõudmine oli peaaegu täidetud. Tegelikult oli mitmeid apteeke, mis pidid teenindama suhteliselt väikest arvu elanikke, näiteks kuulus Pirita apteegi teeninduspiirkonda 2691 inimest ja Lalli apteegi piirkonda 3430 inimest. Samas teenindas Rapla apteek 9441, Kose apteek 8054 ja Keila apteek 8941 inimest (TLA 884. 5. 96, lk 56). Nii pidid paljud apteegid teenindama rohkem rahvast, kui oli nõuetes ette nähtud.

1926. aastaks olukord paranes, sest Hageri jaoskonnas avati abiapteek. 1922. aastal oli Hageri apteegi kohta 7233 inimest, 1926. aastaks elas selles piirkonnas aga 8276 inimest ja oli vaja lisaapteeki, et jõutaks teenindada kõiki inimesi (TLA 884. 5. 139, lk 233).

1923. aastal saatis Tervishoiu Peavalitsus kõikidele maakondade ja linnade tervishoiuosakondadele kirja, kust selgub, et Eesti apteekide töös esines mitmeid puudusi. Mõnel apteegil polnud korras paberid või olid täitmata mõningad nõuded, näiteks olid korrast ära kaalud ja kaaluvihid, hoidenõud ei olnud puhtad ja ka üldine puhtus jättis nii mõneski apteegis soovida. Üks punkt, mida ka Harjumaa apteekides tihti ei täidetud, puudutas rohtude hindu: 8) Apteegi seaduslisest taksist peab kinni peatama aga ei ole lubatud omavolilist hindade muutmist, olgugi mõni rohi sisseostes kallim (TLA 884. 5. 96, lk 5). Arstid kaebasid, et apteekrid petavad rahvast, küsides ravimite eest rohkem kui ette nähtud (TLA 884. 5. 74, lk 198). Ravimite hinna tõstmine raskendas nende kättesaadavust haigetele. Lisaks hindade tõstmisele süüdistasid arstid apteekreid ka arstide töö tegemises. Nimelt külastasid osad apteekrid haigeid ja andsid neile kangeid ravimeid. Arstide hinnangul oli tegemist väga suure probleemiga, sest kui apteeker jagas retseptita ravimeid, võis tõesti ravimit vajav arsti retsepti omav patsient jääda sellest ilma, kuna rohi võis olla juba otsas (TLA 884. 5. 74, lk 167; TLA 884. 5. 74, lk 198). Selline asi oli võimalik ainult siis, kui apteeker ei täitnud korralikult pabereid ja seetõttu oli 1923. aasta Tervishoiu Peavalitsuse kirjas esimesena toodud nõue: 1) Kõigis apteekides, nii esimese- kui ka teisejärgulistes, peavad olema ja peetama: retseptuuri, käsimü̈̈gi ja kihvtide nöörraamatuid, ringkirjade ja ametliku kirjavahetuse ("ees- 
kirjade") sissekirjutamise ja alalhoidmise raamat ja laboratooriumi raamat (TLA 884. 5. 96, lk 5). Et hiljem selliseid kaebusi apteekide kohta ei laekunud, võib arvata, et hoiatav kiri mõjus ning apteekides toimuv sai vähemalt mingil määral kontrolli alla.

\section{Kokkuvõtteks}

Käesolevas artiklis käsitleti riigi toetatud meditsiinisüsteemi, mida on seni vähe uuritud. Üks peamisi põhjusi, miks eelistati arstiabile rahvameditsiini, oli arstiabi halb kättesaadavus. Nimelt polnud kõigis arstijaoskondades arste ja arstiabi oli väga kallis. Harjumaa maapiirkondades polnud ühtegi haiglat ja harjumaalased said haiglaravi ainult Tallinnas, mis muutis haiglaravi raskesti kättesaadavaks: lisaks reisikuludele oli haiglaravi kallis. Jaoskonnaarstidel lasus meeletult erinevaid ülesandeid, mis omakorda raskendas arstiabi andmist. Harjumaalaste usaldust riikliku meditsiinisüsteemi vastu kõigutasid juhtumid, kus meditsiinitöötajad võtsid lubatust rohkem raha. Siiski võib öelda, et 1920. aastate teiseks pooleks hakkas olukord paranema ja näiteks 1925. aastaks oli igas arstijaoskonnas olemas vähemalt üks arst. Apteekidesse ja apteekrite poole pöördusid inimesed enne arsti juurde minekut, mis põhjustas vahel konflikte, sest apteekrid ei oleks tohtinud retseptita jagada ravimeid ja teha arsti tööd. Lisaks küsisid apteekrid mõnikord ravimite eest lubatud suuremat hinda, mis raskendas ravimite kättesaadavust ning tekitas usaldamatust apteekrite ja harjumaalaste vahel.

\section{Kommentaar}

${ }^{1}$ Harjumaa oli 1920. aastatel palju suurem kui tänapäeval, hõlmates suurt osa ka tänapäeva Raplamaast ja väikest osa Läänemaast.

\section{Allikad}

TLA = Tallinna Linnarhiiv

STA = Sanitaar-topograafiline arhiiv

TLA 884. 5. 54. Harju Maakonna Walitsus ... osakond Tallinnas. 13. märts 1921. a.

TLA 884. 5. 71. Harjumaa terwishoiu jaoskonna arstide tegewusülesannete juhatuskiri. 
TLA 884. 5. 71. Harju Maakonna Walitsusele Tervishoiu osakonna juhataja ettepanek mõnede tervishoiu arstide jaoskondade piiride muutmises.

TLA 884. 5. 71. Ärakiri Harju Mk.V. otsusest. 16.06.1922. a. N. 39. p. 359.

TLA. 884. 5. 71. Ringkiri kõigile Harju Maakonna Wallawalitsustele.

TLA 884. 5. 74. Kõnnu Wallawalitsusele. Esitamiseks Harju Maakonna Walitsusele.

TLA 884. 5. 74. Harju Maawalitsuse Tervishoiu Osakond Tallinnas august 1922.a. n. 385 .

TLA 884. 5. 74. Väljalõige Tallinna Töölisest 25. märts. 1922.a. N. 15. Lk. 113.

TLA 884. 5. 74. Harju Maawalitsuse Tervishoiu Osakond Tallinnas märts 1922.a. n. 233.

TLA 884. 5. 74. Harju Maawalitsuse Tervishoiu Osakond Tallinnas november 1922.a. n. 481 , lk 255.

TLA 884. 5. 74. Protokoll Harju Maakonna tervishoiu arstide koosolekule 12. aprill 1922.

TLA 884. 5. 92. Tervishoiuosakonna juhataja ettekanne maakonna nõukogu otsuste 19. ja 20. dets. 1921.a. p. XXIV ja maakonna 1922 aasta eelarwe protesteerimise puhul administratiiw kohtus.

TLA 884. 5. 96. Harjumaa apteekide asukohad, 1922 a. retseptide ja läbimüügi aruanded ning neid ümbritsevad vallad.

TLA 884. 5. 96.Eesti Vabariik. Töö-Hoolekandeministeerium.Tervishoiu Peavalitsus. 22. veebruaril 1923. Nr. 785. Tallinn. Ärakiri.

TLA 884. 5. 96. Eesti Vabariik. Töö-Hoolekandeministeerium Tervishoiu Peavalitsus. 17. jaan.1923. Nr. 319. Ärakiri.

TLA 884. 5. 97. Tervishoiu osakonna juhataja ettepanek tasumaksmises arstidele nende poolt toime pandavate rahvale tervishoidiliste kõnede pidamise puhul, sellekohaste ruumide üürimiseks ja udupildi aparaadi kuluks.

TLA 884. 5. 97. Väljavõte Riigi Teatajast 22. maist 1920. a. Nr. 75/76. Määrused arsti kutsetegevuse kohta.

TLA 884. 5. 106. Protokoll Harju maakonnavalitsuse asjaajamise ja arvepidamise revideerimisest 3.-9.dets. 1924. a.

TLA 884. 5.106. Aruanne. Harju maakonna tervishoidilise seisukorra üle 1923. a.

TLA 884. 5. 106. Harju maakonnavalitsuse Tervishoiu-osakonna ametnikkude tööjaotus 1924. aastal.

TLA 884. 5. 132. Harju maakonnavalitsuse Tervishoiu osakonna 1925. aasta tegevus.

TLA 884. 5. 139. Harjumaa tervishoiu jaoskondade arstide ja ämmaemandate tegevusülesanded ja tasunormid.

TLA 808. 1. 210. Ringkiri Harjumaa vallavalitsustele. 


\title{
Kirjandus
}

HMVT 1927 = Tervishoiu osakond. Harju Maavalitsuse Teataja 19, 9. september, lk 168-169.

Karjahärm, Toomas \& Sirk, Väino 2001. Vaim ja võim. Eesti haritlaskond 1917-1940. Tallinn: Argo.

Oganjan, Kristina 2008. Tervishoid Harjumaal 1922-1926. Bakalaureusetöö. Tallinn: Ajaloo Instituut.

Rahvalugemise 1924 = 1922 a. üldrahvalugemise andmed. Vihk VI. Harju maakond ja Tallinna linn. Tallinn: Riigi Statistika Keskbüroo.

Rammul, Aleksander 1937. Harjumaa tervishoiuline kirjeldus. Tartu: Tervishoiuvalitsus.

Tallinn 1924 = Tallinn. Eesti Statistika 31 (10), kuukiri. 15. oktoober, lk 35.

RT 1924 = Harju Maakonnanõukogu poolt 29. septembril 1923. a. vastu võetud ja kinnitatud määrused külgehakkavate haiguste eest hoidumiseks ja nende vastu võitlemiseks Harju maakonnas. Riigi Teataja 39/40. 11. märts.

\section{Summary}

\section{Healthcare in Harju County during 1922-1926: Employees, Institutions, Access to Health Care}

\author{
Kristina Oganjan
}

Key words: Harju County, medical staff, medicine, pharmacy, rural medical practice

The aim of this work is to study the state-supported health care system in Harju County during the years 1922-1926. This subject has not been studied extensively up until now and the article provides a clearer picture of quondam health service institutions in Harju County, the people working as medical staff and whether medical care was available to people living in rural areas. The focus is on the rural areas of Harju County, and the national health care system as relatively unexplored domains. Therefore, most of the information here is obtained from the Tallinn City Archive. The article does not concern folk medicine, although this was probably used most often. Folk medicine needs separate research and the current one is groundwork for this: it helps to understand why, in the 1920 's, people preferred folk medicine to state-financed medicine.

As a result of the research I found out that poor access to health care was one of the main reasons why ethno-medical treatment was preferred. In some parts of the region there were no doctors and medical care was very expensive. In the rural areas of Harju County, there were no hospitals and people could only use the ones in Tallinn. In addi- 
tion to the fact that it was difficult to travel to Tallinn, hospital treatment was very expensive. After a stay in hospital, many people accrued serious debt. Rural medical practice doctors had many different tasks which made it difficult for people to access health care.

People from Harju County often did not want to go to the doctor because they did not trust medical staff - on several occasions medical personnel took too much money from patients. However, we can say that in the second half of the 1920's the situation started to improve: in 1925, there was at least one doctor in every rural medical practice.

People in Harju County often visited a pharmacist before going to the doctor, and sometimes this led to conflict, because pharmacists sold prescription drugs without permission and thus did the work of the doctors. Likewise, pharmacists sometimes asked a higher price for drugs than allowed, which made it difficult for poor people to access medicines, and again it caused conflict between pharmacists and doctors. 